\title{
MANIFESTACIONES OCULARES EN VIH-S
Análisis de 100 pacientes en el Hospital de San José
}

Nancy Rodríguez $M D^{*}$, Mario Osorio $M D^{*}$, Guillermo Morales $M D^{*}$, Henry Mendoza $M D^{* *}$, Alfonso Tribín MD***

\section{RESUMEN}

Objetivo: establecer cuáles son las manifestaciones oculares (de los segmentos anterior y posterior) más comunes en pacientes con VIH-SIDA en el Hospital de San José y correlacionarlas con los marcadores de actividad de la enfermedad y los informes de la literatura mundial.

Diseño: trabajo de investigación tipo descriptivo, prospectivo.

Participantes: 100 pacientes pertenecientes al programa de VIH - SIDA del Servicio de Infectología del Hospital de San José.

Principales medidas documentadas: examen externo, agudeza visual, examen de biomicroscopía (que incluye córnea y segmento anterior) y examen de fondo de ojo. Los hallazgos se registraron en una tabla diseñada para este fin.

Resultados: de los 100 pacientes examinados se documentó uno con molusco contagioso, dos con orzuelos, seis con blefaritis, una úlcera corneana de características bacterianas, uno con queratitis estromal inespecífica, tres con retinopatía por VIH, un paciente con retinopatía por citomegalovirus (bilateral) y uno con cicatriz de retinocoroiditis por toxoplasmosis.

Conclusiones: a diferencia de la literatura mundial, la retinitis por citomegalovirus no fue el hallazgo más común del segmento posterior en la población de nuestro hospital (solo 1\% ), como sí lo fueron las manifestaciones de retinitis por VIH (exudados, envainamiento vascular, etc.). En cuanto al segmento anterior y la córnea, se observó una úlcera corneana de característica bacteriana, la cual no se ha consignado en la literatura mundial como hallazgo propio de la infección por VIH - SIDA, así como los orzuelos y blefaritis. Enfermedades como molusco contagioso y queratitis inespecífica están relacionadas en la bibliografía con esta enfermedad. No se encontró patología tumoral en la serie estudiada.

\section{Introducción}

Hace más de dos décadas se registró el primer caso de síndrome de inmunodeficiencia adquirida (SIDA). Después se realizó una intensa búsqueda para dar con el agente causal. Desde su identificación, ha sido estudiado como nunca antes en la historia previa de la virología; ningún otro virus ha sido tan ampliamente analizado en un periodo tan corto.

Nuestro conocimiento acerca de esta enfermedad sigue en su pródigo camino de nuevos descubrimientos

Médico Oftalmólogo, Hospital de San José, Bogotá, Colombia Médico Infectólogo, Hospital de San José, Bogotá, Colombia

*** Residente Tercer año de Oftalmología, Hospital de San José, Fundación Universitaria de Ciencias de la Salud, Bogotá, Colombia y avances en cuanto a la terapia, así como sobre las vacunas que han comenzado a considerarse como posible solución para esta pandemia mundial que ha cobrado la vida de tantas personas, sobre todo en países en vía de desarrollo, en especial en África, donde se calcula que alrededor de 27 millones de personas están infectadas por el virus del VIH.

La literatura mundial registra varias series de casos que correlacionan la patología oftalmológica con la enfermedad de VIH-SIDA. Hasta ahora en la literatura colombiana no hay estudios previos ni datos estadísticos o epidemiológicos que involucren pacientes infectados y hallazgos oftalmológicos.

El Hospital Universitario de San José se ha convertido en centro de remisión de pacientes con 
VIH-SIDA, cuyo Servicio de Infectología tiene estadísticas disponibles. Esto nos permitió realizar un trabajo con el objetivo de documentar las manifestaciones oculares de esta enfermedad en nuestra población general.

\section{Descripción del problema}

Los datos acerca del número de personas contagiadas con esta enfermedad no son precisos, debido a factores económicos que impiden el buen trabajo de campo en cuanto a la recolección de información. Además, el factor social y las creencias populares o de cada persona, hacen que los datos obtenidos por los servicios de salud no sean confiables.

Por lo anterior surge una pregunta importante: ¿cuáles son las manifestaciones oculares más frecuentes en los pacientes que sufren de VIH-SIDA en la población colombiana, en especial la de Bogotá?

\section{Materiales y métodos}

Previo al examen de los pacientes, se revisaron las historias clínicas del Servicio de Infectología del Hospital de San José y se tomaron 100 de ellas en forma aleatoria, en especial aquellas con datos de exámenes paraclínicos más completos. Se examinaron los 100 pacientes escogidos con diagnóstico de VIH-SIDA, durante el periodo comprendido entre enero y junio del año 2003. Se interrogó a cada uno acerca de la sintomatología, cambios en la agudeza visual, lagrimeo, secreción purulenta o dolor, entre otros. Después se practicó examen oftalmológico completo, que incluía piel palpebral, agudeza visual, evaluación de reacción pupilar, movimientos oculares, estudio biomicroscópico bajo lámpara de hendidura y fondo de ojo indirecto con dilatación pupilar.

Los datos recogidos se tabularon, según el modelo elaborado para dicho propósito. Una vez identificados los positivos en el examen físico, se registraron con fotografía.

\section{Criterios de inclusión}

Todos los pacientes del Servicio de Infectología del Hospital de San José que en forma voluntaria desearan entrar a este estudio, sin importar la edad, sexo, raza o condición social. Se les dió la información suficiente sobre el estudio, la utilidad para ellos y el hospital, teniendo en cuenta que es necesario hacer un seguimiento de la enfermedad y de las posibles manifestaciones clínicas de cada uno de ellos.

\section{Criterios de exclusión}

Se excluyeron aquellos que por voluntad propia no quisieron ser tenidos en cuenta en este estudio, o que su estado general imposibilitara la toma del examen, así como las fotos que se requieren para la documentación de las posibles complicaciones encontradas en el globo ocular, párpados o sus anexos.

\section{Análisis estadístico}

Las variables categóricas se presentan como porcentajes.

\section{Resultados}

1. Distribución por promedio de edad: se encontró un rango de edad entre 21 y 61 años, con promedio para los hombres de 33,67 y las mujeres de 33,83 .

2. Distribución por sexo: durante el estudio se encontró una preponderancia del sexo masculino, $88 \%$, contra el 12\% del femenino (Figura 1).

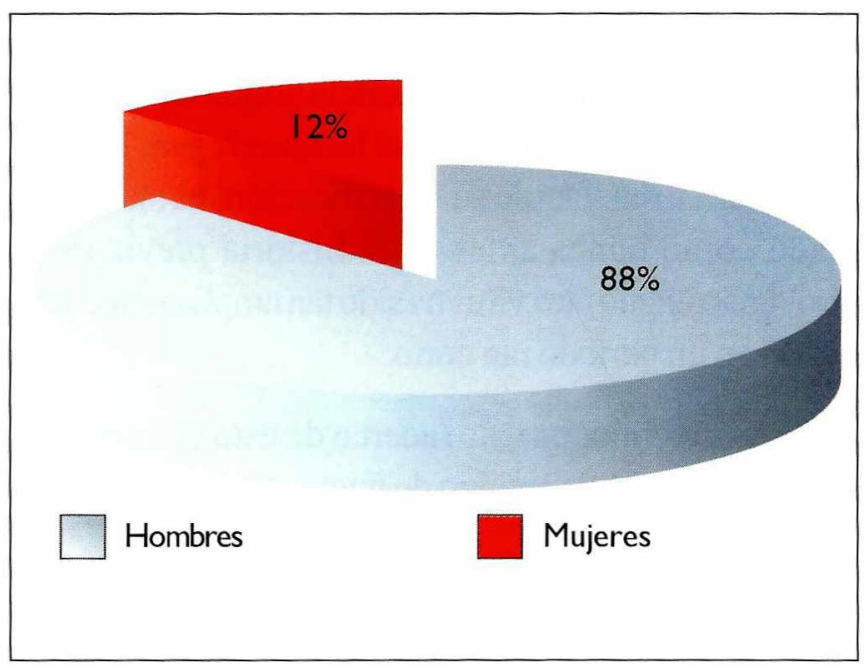

Figura I. Distribución por sexo. 
3. Sintomatología: el 56\% estaba asintomático durante el momento de la entrevista. Solo el $16 \%$ tenía disminución de la agudeza visual, $12 \%$ aquejaba ojo seco y en un menor porcentaje había sintomatología de secreción, dolor y lagrimeo (Figura 2).

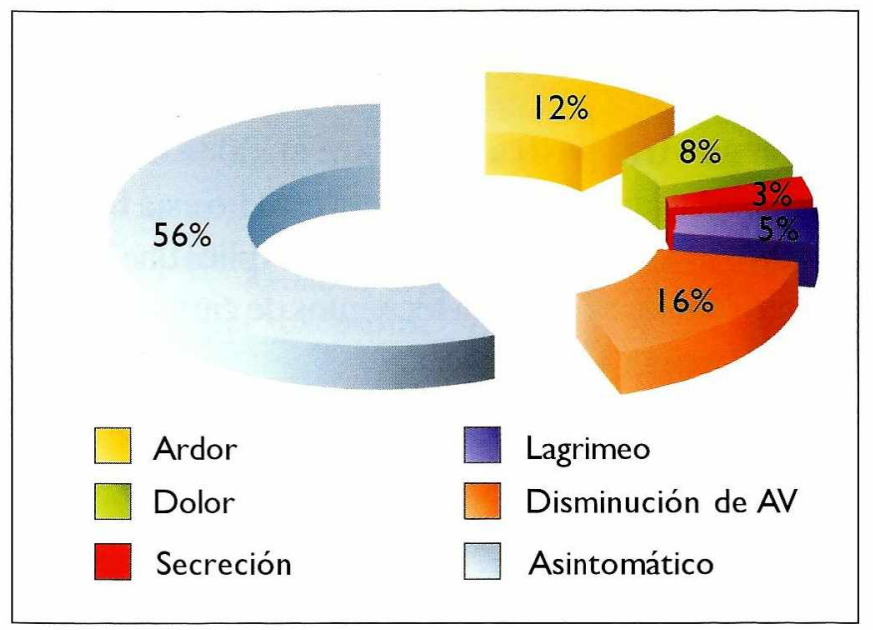

Figura 2. Sintomatología ocular más frecuente.

4. Agudeza visual: la mayoría de los pacientes entrevistados tenía buena agudeza visual. El $71 \%$ estaba entre 20/20 y 20/50, el $25 \%$ oscilaba entre 20/60 y $20 / 100$, el $3 \%$ variaba entre 20/200 y 20/400. Sólo uno estaba legalmente ciego (visión de no percepción de luz) y tenía antecedente de retinitis por citomegalovirus (Figura 3).

\section{Examen externo y segmento anterior bajo bio-} microscopía: durante esta parte del examen se tuvo especial precaución en la presencia de lesiones compatibles con molusco contagioso, aunque se recolectaron como datos positivos otros elementos para tener en cuenta como orzuelo, chalazión y blefaritis.

Examen externo y biomicroscopía (Figura 4 ): se encontró un paciente con molusco contagioso (Figura 5), seis con blefaritis (6\%), dos con orzuelos ( $2 \%$ ), con queratitis inespecífica (Figura 6) y uno con úlcera corneana (Figura 7), que por las características correspondía a origen bacteriano; se le hizo Gram y cultivo, con resultados inespecíficos. Recibió prescripción médica con ciprofloxacina colirio una gota cada hora durante diez días y ciprofloxacina ungüento oftálmico

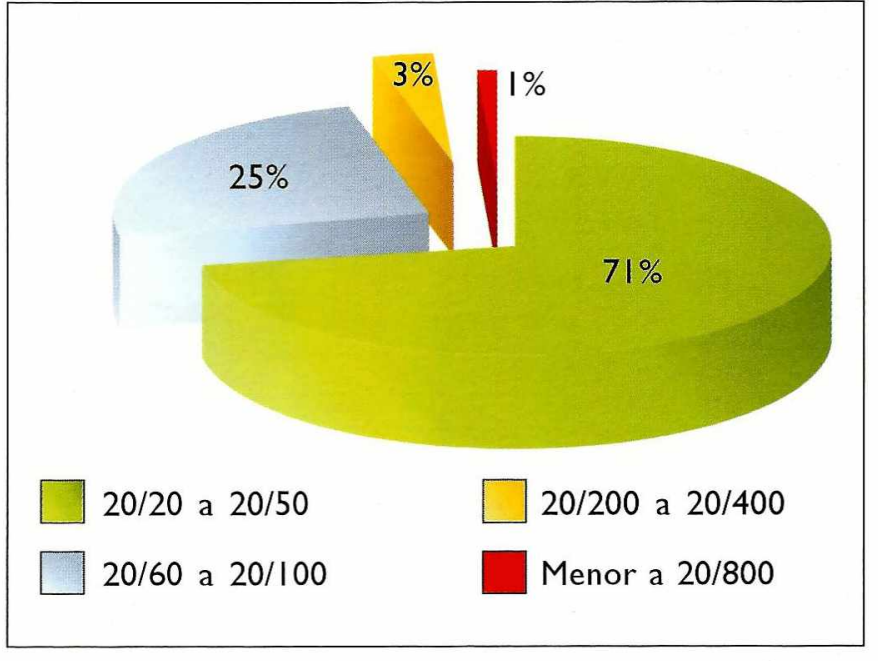

Figura 3. Agudeza visual.

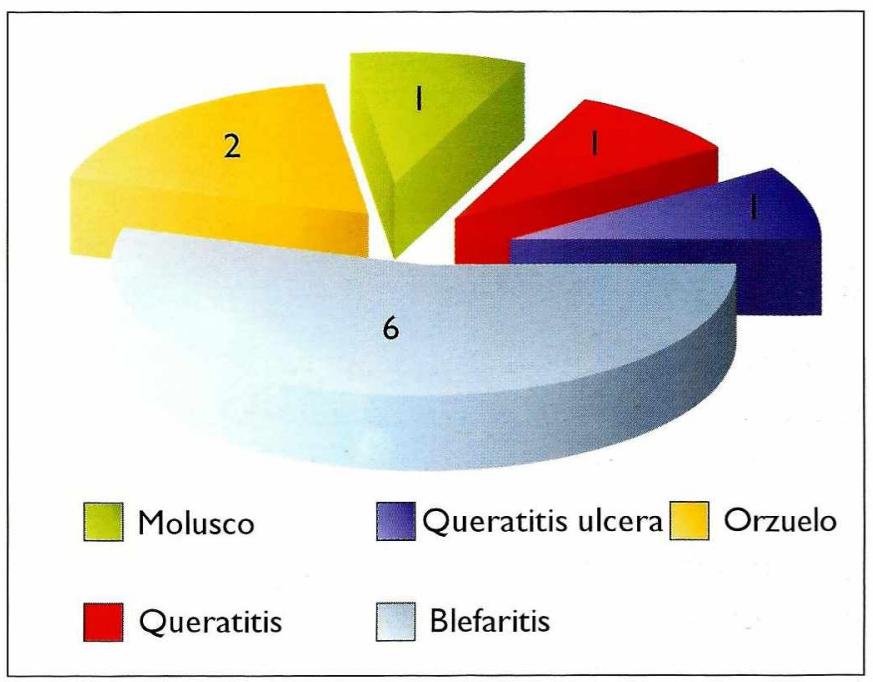

Figura 4. Hallazgos positivos durante el examen externo y biomicroscopía.

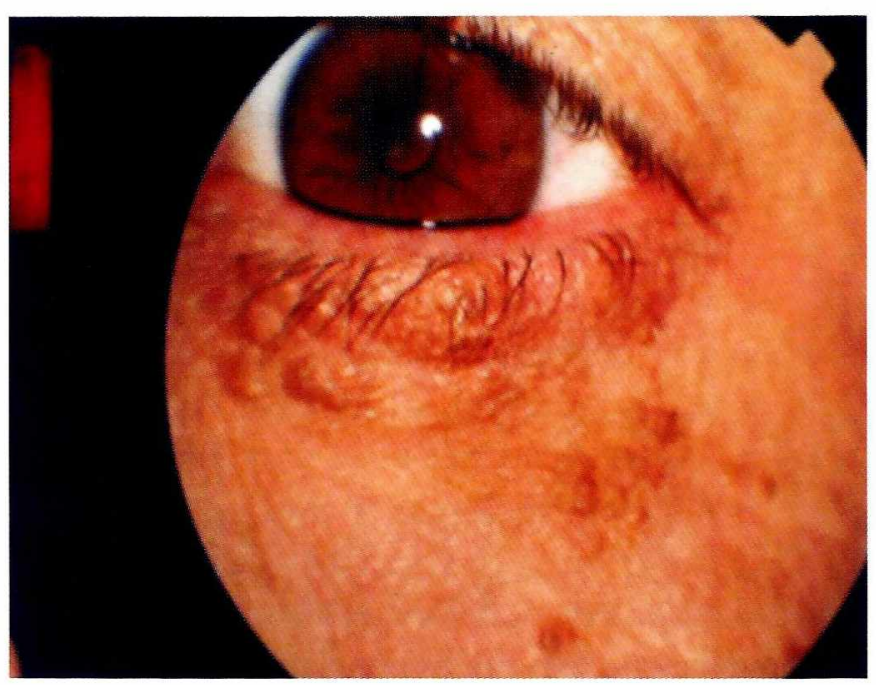

Figura 5. Molusco contagioso. 


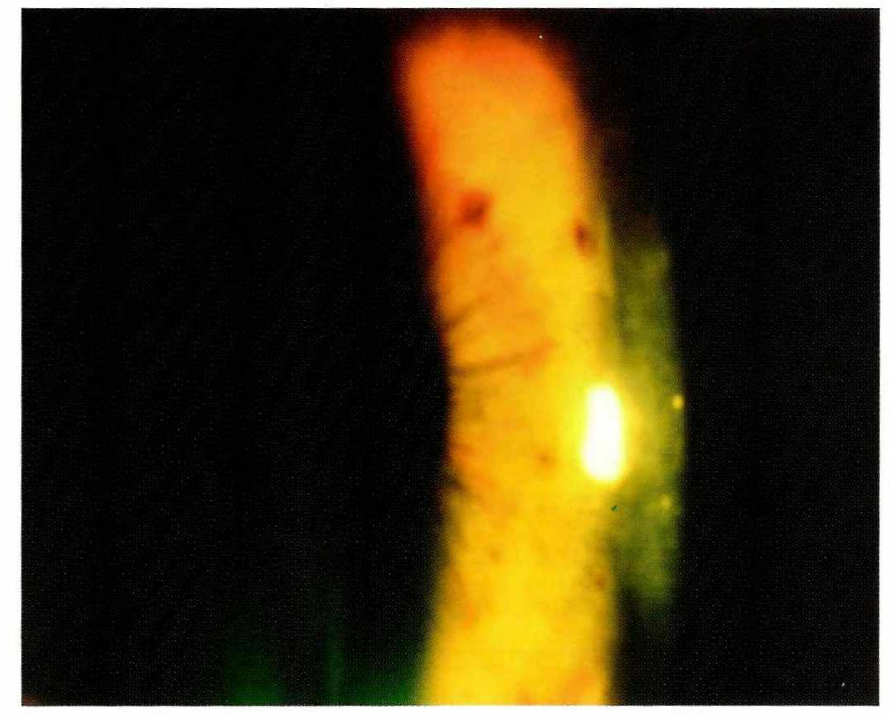

Figura 6. Queratitis inespecifica.

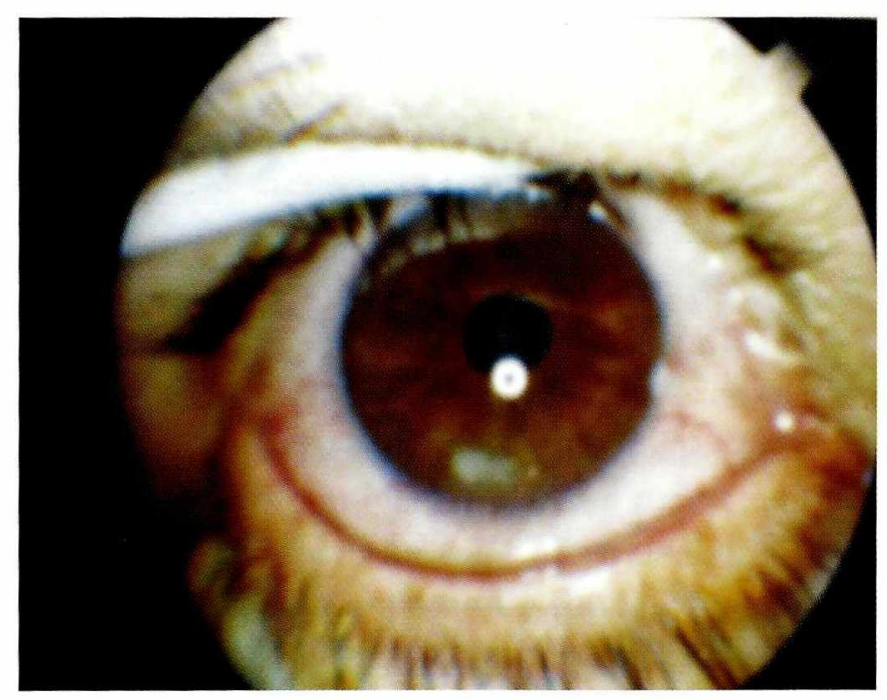

Figura 7. Úlcera corneana bacteriana.

en la noche durante el mismo periodo, con resolución de la sintomatología y de la lesión.

6. Examen de fondo de ojo: durante el examen encontramos los siguientes hallazgos (Figura 8): un paciente con cicatrices de coriorretinitis por citomegalovirus (bilateral) legalmente ciego (visión actual de no percepción de luz ambos ojos) (Figura 9); un paciente con cicatriz de coriorretinitis posiblemente por toxoplasmosis (Figura 10) y dos (2\%) con retinitis por VIH. Estos últimos no se pudieron documentar con fotografías por el mal estado general que impidió la movilización de los mismos.
7. Recuento promedio de CD4: el $29 \%$ de los pacientes del estudio tiene un recuento de CD4 mayor a $600 \mathrm{cl} / \mathrm{ml}$, debido a que actualmente reciben tratamiento, lo cual explica que no haya mayor número de manifestaciones oculares dentro del estudio (Figura 11).

\section{Recuento de CD 8 pretratamiento (Figura 12).}

9. Carga viral postratamiento: el $100 \%$ de los pacientes examinados durante el estudio está bajo un régimen de medicamentos, lo que explica que la gran mayoría de ellos tenga recuentos de carga viral bajos (Figura 13).

\section{Conclusiones}

El estudio nos permite concluir lo siguiente:

- Los pacientes vistos durante este periodo no tienen importantes manifestaciones oculares, en vista que son individuos que presentan baja carga viral e índices casi normales de CD4 y CD8. Esto explica el control sobre las enfermedades infecciosas oportunistas y por ende, el bajo número de presentación de casos oculares.

- A pesar de ser pacientes con alto riesgo de infección por su estado de inmunosupresión, la mayoría cuenta con niveles aceptables de linfocitos auxiliadores (helper) para mantener un equilibrio entre salud y enfermedad.

- La clínica inicial de estos enfermos es variada. Según la literatura mundial la molestia ocular y lagrimeo son los más frecuentes, dato que coincide con nuestros pacientes.

- La pérdida de visión se explica por defectos refractivos, más no por lesiones o daños producidos por otros agentes etiológicos.

- En un solo caso bajo examen se pudo diagnosticar, la presencia de ceguera secundaria a citomegalovirus.

- Manifestaciones infecciosas como las de molusco contagioso son de baja presentación en la literatura mundial al igual que en nuestra serie. 


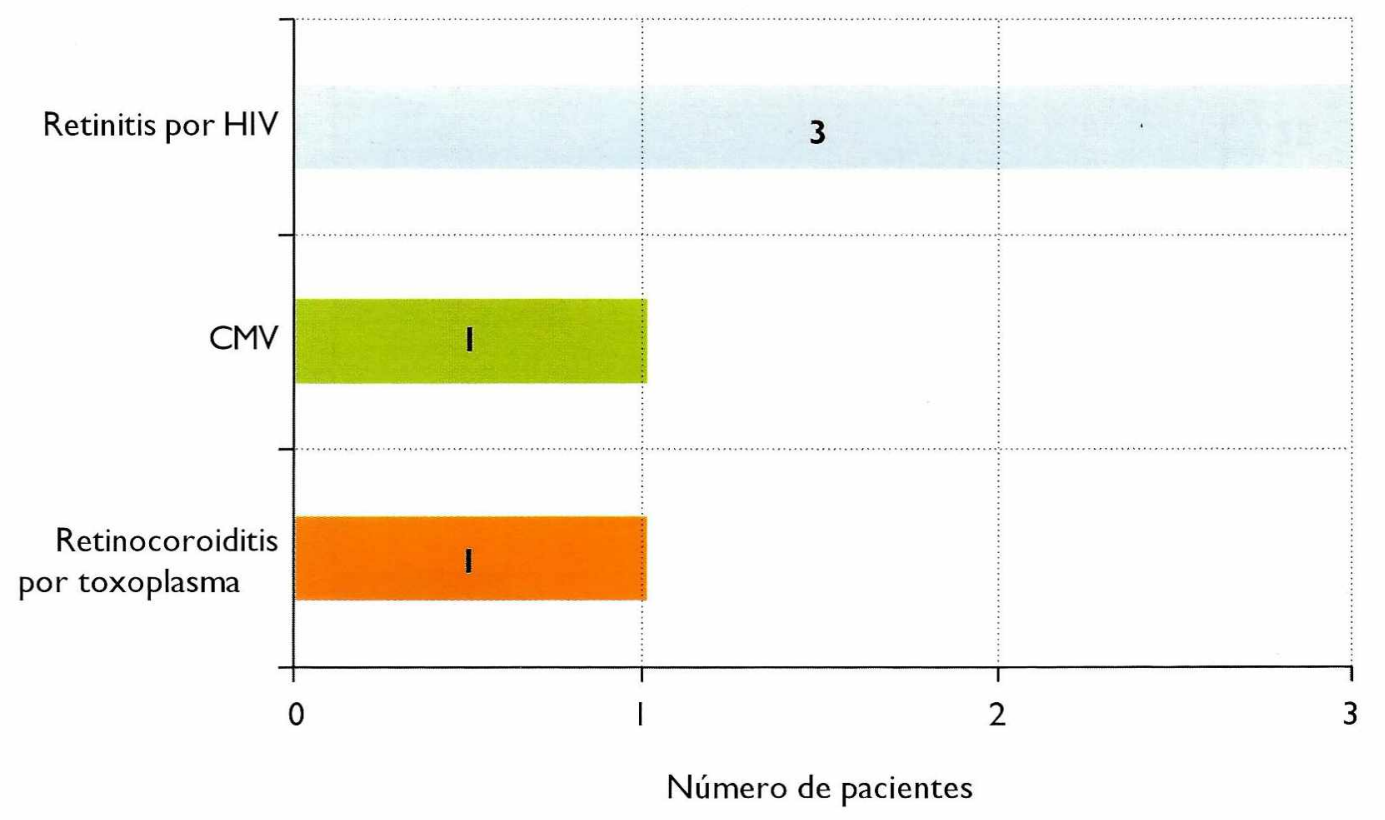

Figura 8. Hallazgos positivos en examen de fondo de ojo.

- No encontramos patología tumoral en nuestros pacientes. La literatura reporta hasta el $10 \%$.

- Se encontraron otros datos importantes como blefaritis y orzuelos que pueden no corresponder a patología asociada con la enfermedad de base.

- La mayor parte de los pacientes de la presente serie no tiene sintomatología, lo que lleva a pensar que

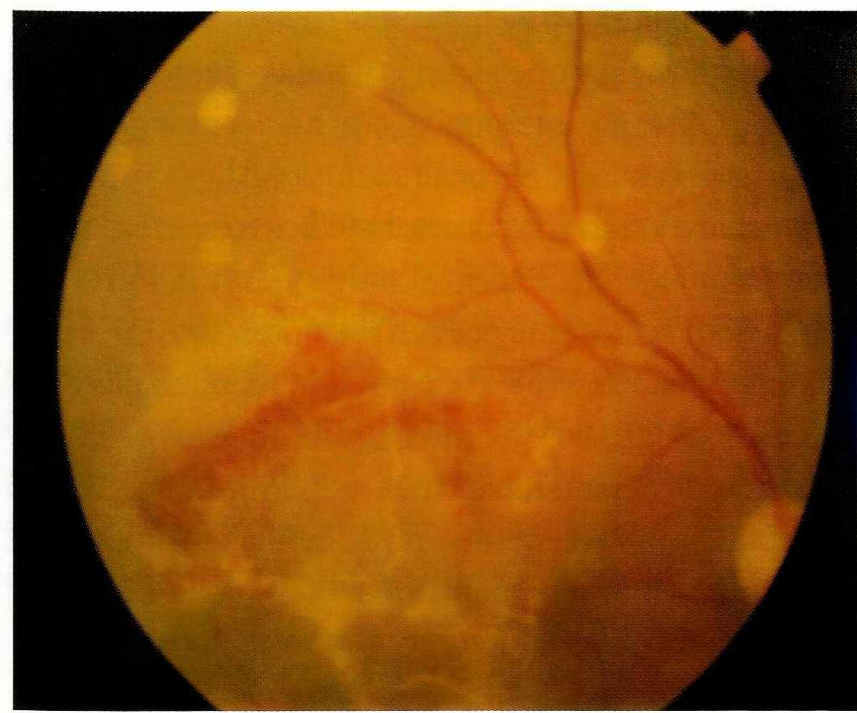

Figura 9. Secuelas de retinitis por citomegalovirus. Visión actual de no percepción de luz en ambos ojos. oftalmológicamente se encuentran sanos. Aunado a esto, observamos los reportes de CD4 altos y carga viral bajos, que disminuyen la frecuencia de presentación de síntomas oculares.

- La mayoría tiene buena agudeza visual, lo que se manifiesta clínicamente con hallazgos normales en el examen de fondo de ojo.

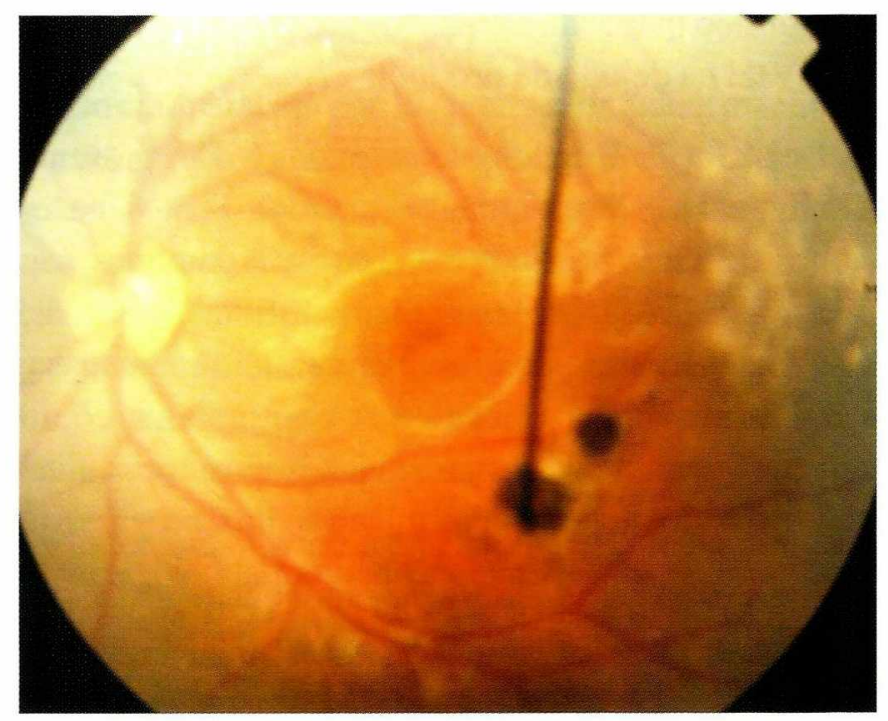

Figura I 0. Cicatriz en área macular posiblemente secundaria a retinocoroiditis por toxoplasmosis. 


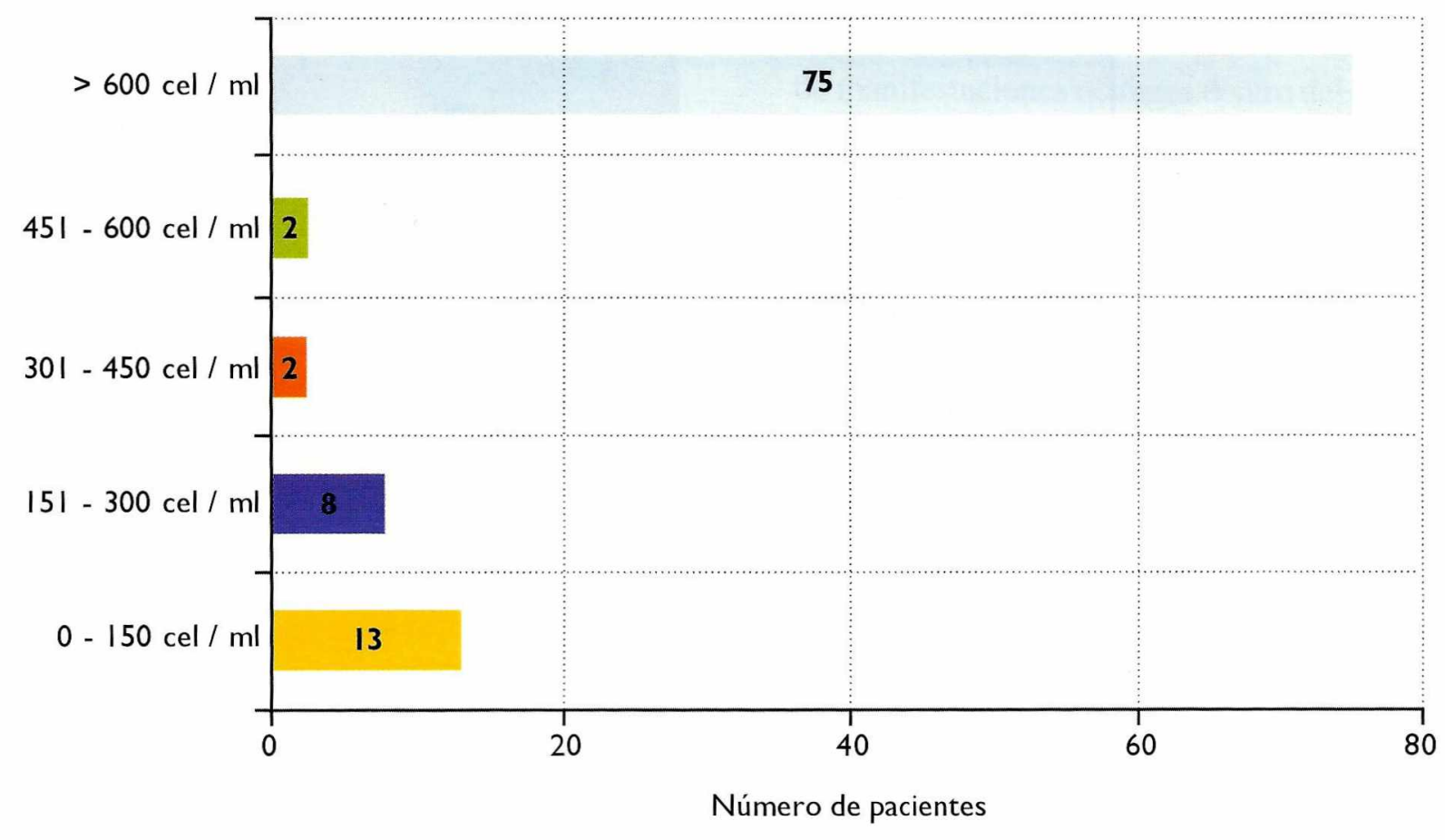

Figura II. Recuento de CD4 en la población estudiada.

\section{Discusión}

Los estragos socioeconómicos causados por el SIDA son incalculables. No hay un estimado real para intentar entender la pérdida incalculable de vidas y el potencial económico que cada uno de los pacientes infectados para VIH ha dejado de producir.

Del 40 al $70 \%$ de los pacientes con SIDA presenta signos oculares de enfermedad y cerca al $95 \%$ tiene lesiones oculares postmortem. Las más comunes son microvasculatura retiniana (infarto de fibras nerviosas, manchas blancoalgodonosas, hemorragias retinianas y microaneurismas), infecciones oportunistas como citomegalovirus (CMV), sarcoma de Kaposi conjuntival y de párpados, necrosis retiniana aguda progresiva, neuropatía óptica y alteraciones neurooftalmológicas.

Mediante una variedad de técnicas, incluyendo cultivos directos, inmunohistoquímica para antígenos virales y en especial mediante el análisis de la cadena de reacción de polimerasa, el VIH tipo I ha sido demostrado en la mayoría de las estructuras del ojo en pacientes infectados. También ha sido aislado del líquido del humor acuoso, humor vítreo y de la película lagrimal.

Es conocido que la córnea en situaciones normales posee cierto número de linfocitos en ausencia de actividad inflamatoria y que algunos tienen receptores de superficie CD4 que interactúan con el receptor del VIH. Este tipo de células se encuentra a nivel del limbo y esporádicamente central en la córnea. Estudios recientes de anticuerpos monoclonales para el antígeno core del VIH p15 Y p24 demuestran que pueden estar presentes en la córnea en el 2 al 3\%, sobre todo en células epiteliales de la misma. Los intentos por infectar fibroblastos de la córnea en cultivos han sido infructuosos. Sin embargo, si la infección por VIH en este tipo de células se produce in vivo, debe ser por mecanismos diferentes a los de receptores de virales directos, porque este tipo de células no posee uniones CD4.

Se han hallado células de Langerhans migrando hacia la córnea central, expresando HLA II, CD4 y otros 


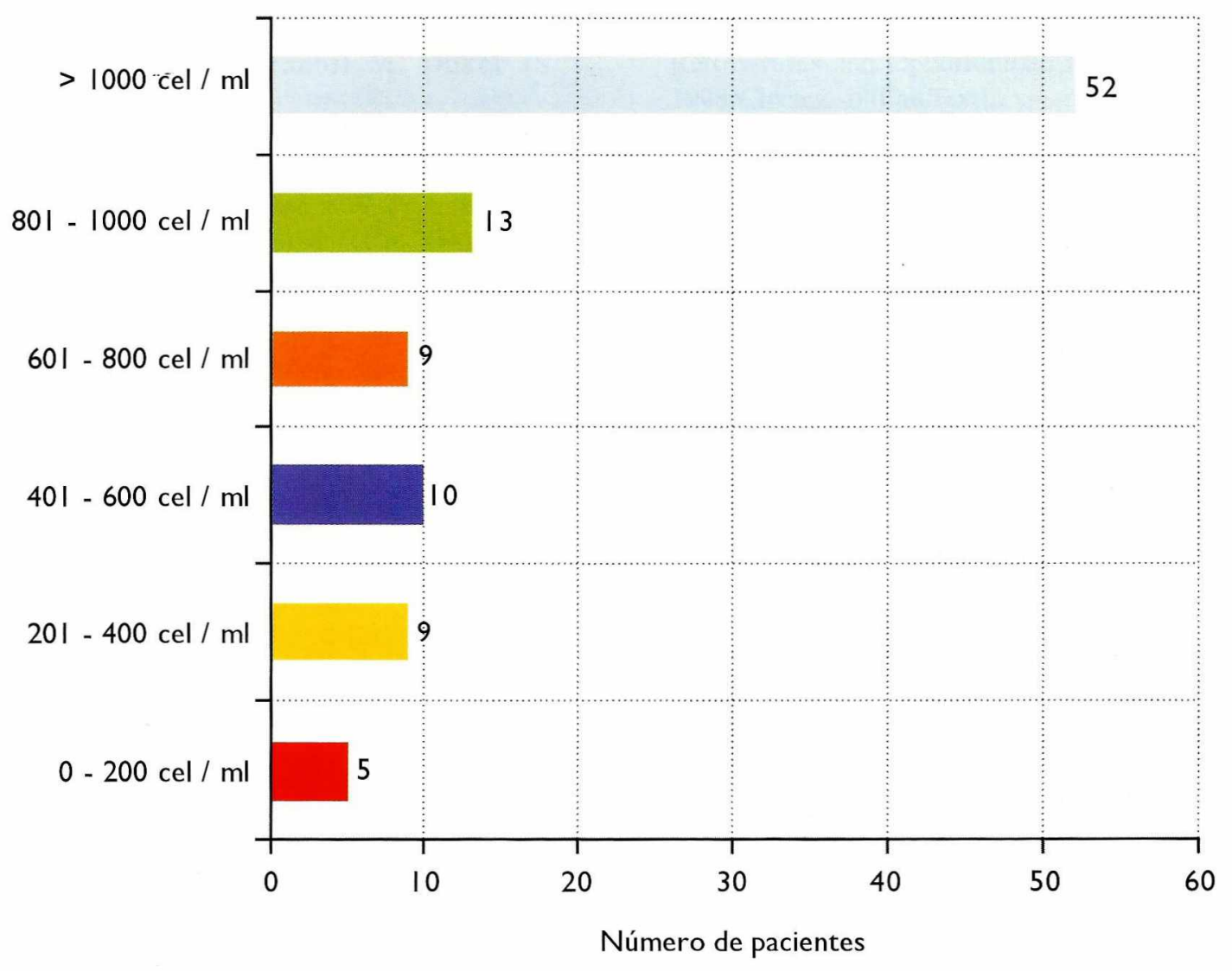

Figura 12. Recuento de CD8 pretratamiento. No todos los pacientes tienen este recuento postratamiento.

receptores que están implicados en el VIH. La retina parece ser el sitio más implicado del ojo en este tipo de infección. Ha sido estudiado bajo inmunohistoquímica, encontrando macrófagos infectados con VIH, así como antígenos de VIH aislados en el endotelio de la microvasculatura retiniana.

La mayoría de los pacientes en nuestra serie estudiada no presentaba sintomatología ocular importante. Cuando la hubó, la más común fue ojo seco, que se correlaciona con la infiltración de la glándula lagrimal por linfocitos, lo que conlleva a una disminución en su producción normal. Este síntoma se describe en la literatura como uno de los más frecuentes.

El signo más característico de retinopatía asociada con SIDA es la presencia de manchas blancoalgodonosas. Se relaciona con la presencia de microvasculopatía en casi el $100 \%$ de los pacientes y por lo regular no se asocian con infección retiniana secundaria. Otro dato importante es el compromiso del nervio óptico, el cual se afecta con pérdida de axones y degeneración del mismo.

En comparación con la literatura mundial, la retinitis por citomegalovirus no fue el hallazgo del segmento posterior más común en nuestro hospital (1\%); es posible que esto se explique porque $100 \%$ de los pacientes estaba recibiendo tratamiento antirretroviral, lo que hace que progresivamente la carga viral disminuya y el recuento de CD4 aumente, con un menor riesgo de complicaciones retinianas de origen infeccioso.

Diferentes autores a nivel mundial coinciden en que el hallazgo más común en la retina es la llamada retinopatía por VIH (exudados, envainamiento vascular, etc.), lo que concuerda con nuestros hallazgos.

En cuanto a las manifestaciones del segmento anterior y la córnea, se documentó una úlcera corneana de 


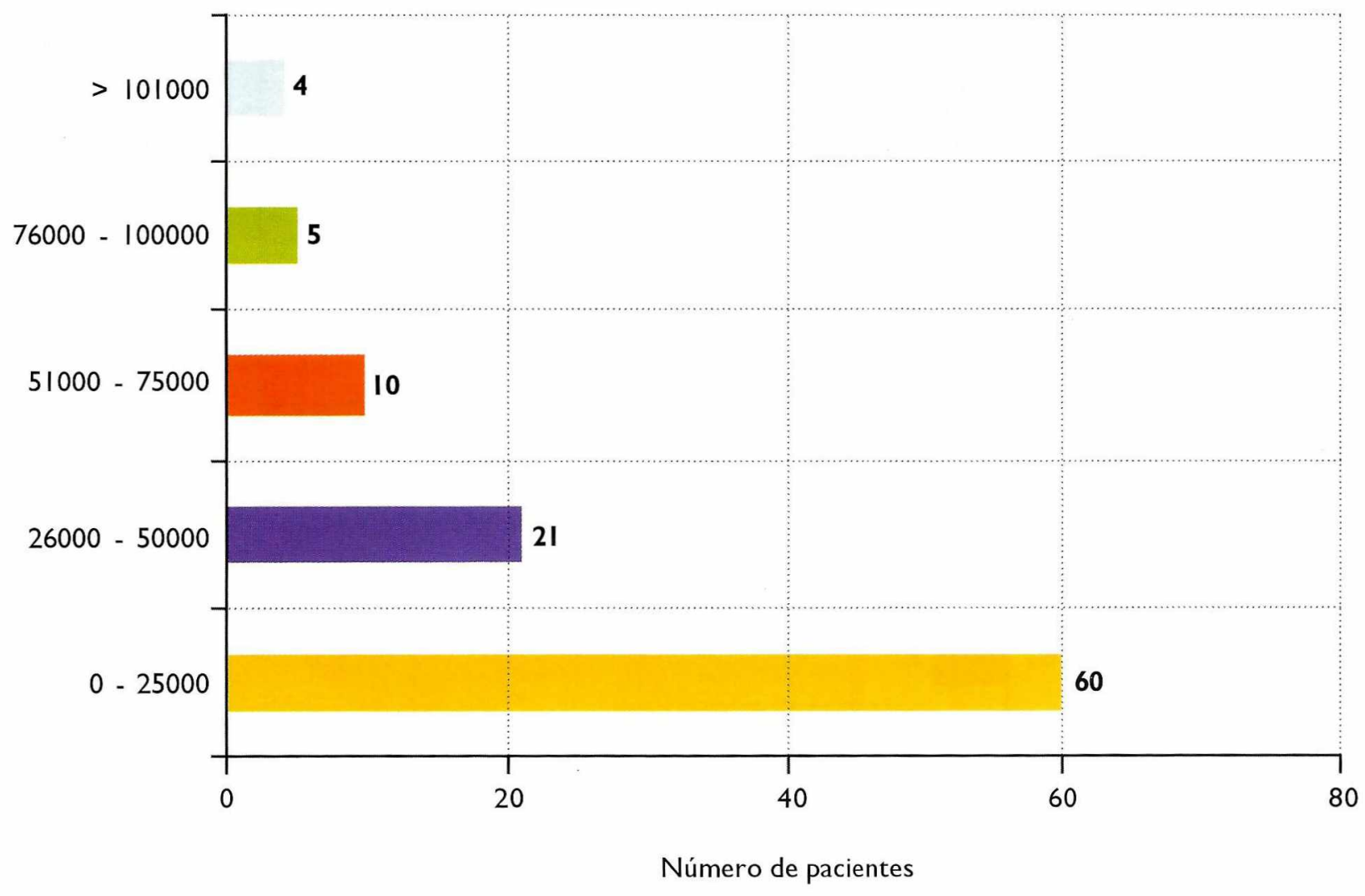

Figura 13. Carga viral postratamiento.

característica bacteriana, la cual no se acepta en la literatura mundial como hallazgo propio de la infección por VIH-SIDA, lo mismo que los orzuelos y la blefaritis. Lo anterior, aunque no es patognomónico de la enfermedad, sí puede tener relación por cuanto la reducción de las defensas del sistema inmune promueve la predisposición hacia infecciones generalizadas o focales. Enfermedades como molusco contagioso y queratitis inespecífica están relacionadas en la literatura mundial con esta enfermedad. No se encontró patología tumoral en la serie estudiada.

\section{Agradecimientos}

Agradecimiento especial al doctor Álvaro Enrique Sanabria, Coordinador de Investigaciones, Facultad de Medicina, Fundación Universitaria de Ciencias de la
Salud, por su valiosa colaboración en la consecución de los resultados de este estudio.

\section{Lecturas recomendadas}

1. Becerra LI, Ksiazek SM, Savino PJ, et al. Syphilitic uveitis in human immunodeficiency virus-infected and noninfected patients. Ophthalmology 1989 Dec; 96(12): $1727-$ 30[Medline].

2. Duane's Ophthalmology [book on CD-ROM]: Ophthalmic disorders associated with selected primary and acquired immunodeficiency diseases. Based on: Tasman W. Duane's Ophthalmology. Lippincott-Raven Publishers; 1998.

3. Flood JM, Weinstock HS, Guroy ME, et al. Neurosyphilis during the AIDS epidemic, San Francisco, 1985-1992. J Infect Dis 1998 Apr; 177(4): 931-40[Medline].

4. Musch DC, Martin DF, Gordon JF, et al. Treatment of cytomegalovirus retinitis with a sustained-release ganciclovir implant. The Ganciclovir Implant Study Group. N Engl J Med 1997 Jul 10; 337(2): 83-90[Medline]. 
5. Ophthalmology [book on CD-ROM]: Cytomegalovirus. Based on: Yanoff M, Duker JS. Ophthalmology. Mosby Inc; 1998.

6. Ophthalmology [book on CD-ROM]: Progressive outer retinal necrosis. Based on: Yanoff M, Duker JS. Ophthalmology. Mosby Inc; 1998.

7. Principles and Practice of Ophthalmology [book on CDROM]: AIDS and its ophthalmic manifestation. Based on: Albert DM, Jakobiec FA, McMullen WW. Principles and Practice of Ophthalmology. WB Saunders Co, 2000.

8. Rachlis A, Palmer R, Doswell M. Improved survival time and
CD4 slope associated with recent advances in HIV antiretroviral therapy as appearing in AIDS Knowledge Base. In: Program and abstracts of the 5th Conference on Retroviruses and Opportunistic Infections. February 1-5, 1998; Chicago, Ill[Full Text].

9. Rao N, Blackman H, Franklin R. Intraocular inflammation and uveitis. In: Basic and Clinical Science Course. Vol 9. BMJ Publishing Group; 1998, p. 157-175.

10. Rickman L, Freeman W. Retinal Disease in HIV-Infected Patients. Retina 1999; 2: 1576-1622.

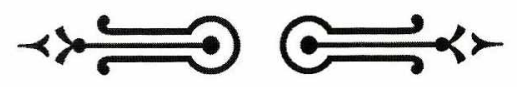

\section{FUNDACIÓN UNIVERSITARIA DE CIENCIAS DE LA SALUD HOSPITAL DE SAN JOSE}

Personería Jurídica No. 10917 del 01-12-1976 Resolución Ministerio de Educación Nacional No. 0125

acultad de Instrumentación Quirúrgica

Código ICFES 270246100281100111100

Título otorgado

Instrumentador Quirúrgico
Oficina de admisiones: Calle 10 No. 18-75 Edificio docente, $1^{\text {er }}$ piso PBX. 5998977 • 5998842 TELEFAX 2019867 • 2018938

E-mail: instrumentacion@fucsalud.edu.co

hppt: www.fucsalud.edu.co

tis in

f

f

\begin{tabular}{|c|c|c|c|}
\hline IESTRE & II SEMESTRE & III SEMESTRE & IV SEMESTRE \\
\hline $\begin{array}{l}\text { Biología } \\
\text { Morfofisiología I } \\
\text { Física } \\
\text { Química } \\
\text { Introducción a la } \\
\text { instrumentación } \\
\text { - Comunicación } \\
\text { oral y escrita } \\
\text { - Informática }\end{array}$ & $\begin{array}{l}\text { - Microbiología } \\
\text { - Ecología } \\
\text { - Morfofisiología II } \\
\text { - Esterilización } \\
\text { - Bioquímica } \\
\text { - Técnicas } \\
\text { quirúrgicas I } \\
\text { - Técnicas de } \\
\text { instrumentación } \\
\text { - Sociología }\end{array}$ & $\begin{array}{l}\text { - Patología I } \\
\text { - Cuidados básicos } \\
\text { en salud } \\
\text { - Estadística } \\
\text { - Farmacología } \\
\text { - Anestesia } \\
\text { - Técnicas } \\
\text { quirúrgicas II } \\
\text { - Técnicas de } \\
\text { instrumentacion II } \\
\text { - Ingés I } \\
\text { - Psicología }\end{array}$ & $\begin{array}{l}\text { - Patología II } \\
\text { - Epidemiología } \\
\text { - Técnicas } \\
\text { quirúrgicas III } \\
\text { - Técnicas de } \\
\text { instrumentación II } \\
\text { - Inglés II } \\
\text { - Constitucion } \\
\text { política } \\
\text { y derecho en salud } \\
\text { - Ética general } \\
\text { - Administración } \\
\text { general } \\
\text { - Investigación I }\end{array}$ \\
\hline
\end{tabular}

